\title{
ANALISIS PEKEMBANGAN PASAR PADA RENCANA PEMBANGUNAN PASAR AGROPOLITAN DESA KAYUMAS KABUPATEN SITUBONDO
}

\section{AN ANALYSIS OF MARKET DEVELOPMENT IN AGROPOLITAN MARKET DEVELOPMENT PLAN OF KAYUMAS VILLAGE, SITUBONDO DISTRICT}

\author{
Yudistira Harisandi ${ }^{1)}$ Muhammad Iqbal Ansory ${ }^{2)}$ \\ 1yudhistira.yt94@gmail.com \\ ${ }^{1,2}$ Fakultas Ekonomi, Universitas Abdurachman Saleh Situbondo
}

\begin{abstract}
ABSTRAK
Penelitian ini akan menganalisis tentang pembangunan ekonomi yang ada di desa, strategi apa saja yang akan dilakukan pemerintah untuk meningkatkan perekonomian di desa dengan cara memenuhi kebutuhan dengan mengandalkan pasar rakyat meskipun ada sebagian lagi penduduk mengandalkan pasar modern dalam memenuhi kebutuhannya. Menurut undang-undang nomor 6 tahun 2014 tentang Desa; desa adalah kesatuan masyarakat hukum yang memiliki batas wilayah yang berwewenang untuk mengatur dan mengurus urusan pemerintahan, kepentingan masyarakat setempat berdasarkan prakarsa masyarakat, hak asal usul, dan/atau hak rakyat yang dialami atau dihormati dalam sistem pemerintahan Negara Kesatuan Republik Indonesia. Dari ketentuan pasal 1 angka 43 tentang pemerintahan daerah di atas dapat diketahui bahwa UU 23/2014 mengakui adanya otonomi yang dimiliki oleh desa. Di samping otonomi yang dimilikinya, desa juga dapat menerima/ melaksanakan suatu urusan pemerintahan tertentu yang berupa penugasan ataupun pendelegasian dari pemerintah pusat ataupun pemerintah daerah. Sejak disahkannya Undang-undang Nomor 7 Tahun 2014 tentang Perdagangan, maka pasar rakyat telah berubah penyebutannya menjadi Pasar Rakyat dengan tetap memperhatikan kekhususan pasar rakyat terkait aspek lokasi yang bersifat tetap berupa toko/kios/los dan bentuk lainnya serta menjadi tempat jual beli dengan proses tawar menawar. Rencana pembangunan Pasar Umum yang berlokasi di Kayumas sejalan dengan tujuan Pemerintah Kabupaten Situbondo menuju kota wisata tahun 2019, untuk mengeksplor daerah Kayumas dengan potensi yang dimiliki. Judul penelitian "Analisis Perkembangan Pasar Pada Rencana Pembangunan Pasar Agropolitan Desa Kayumas Situbondo" dibuat sesuai dengan kondisi pasar di Kayumas. Hasil dari penelitian ini diharapkan memiliki kontribusi besar terhadap pembangunan ekonomi Kabupaten Situbondo.
\end{abstract}

Kata Kunci: Pembangunan, Perekonomian, Pasar Tradisional 


\section{ABSTRACT}

This study will analyze the economic development in the village, about what strategies that will be taken by the government to improve the economy in the village by meeting the needs by relying on people's markets even though there are some people who rely on modern markets to meet their needs. According to Law Number 6 of 2014 concerning Villages; village is a legal community unit that has the authority to manage and handle the government affairs, the interests of the local community based on community initiatives, original rights, and / or people's rights that are experienced or respected in the system of government of the Unitary Republic of Indonesia. From the provisions of Article 1 Number 43 regarding the regional administration above, it can be seen that Law 23/2014 recognizes the autonomy that is owned by the village. In addition to the autonomy a village has, it can also receive / carry out certain government affairs in the form of assignments or delegations from the central or regional government. Since the enactment of Law Number 7 of 2014 concerning Trade, people's market has changed its name to the People's Market by taking into account the specificity of the people's market related to the location aspect that is permanent in the form of shops / kiosks / stalls and other forms as well as being a place of sale and purchase with a bargaining process bid. The plan to build a Public Market located in Kayumas is in line with the objectives of the Situbondo Regency Government towards a tourist city in 2019, to explore Kayumas with its potential. The title of the research "Analysis of Market Development in the Agropolitan Market Development Plan of Kayumas Situbondo Village" was made in accordance with the market condition in Kayumas. The result of the research is expected to have a major contribution to the economic development of Situbondo Regency.

Keywords: Development, Economy, Traditional Markets

\section{PENDAHULUAN}

Pasar merupakan sebuah tempat dimana masyarakat dapat memperoleh barang-barang untuk memenuhi kebutuhan pokok harian, pasar juga memiliki fungsi penggerak ekonomi daerah, tempat terjadinya distribusi hasil produksi masyarakat daerah sehingga kelangsungan operasional pasar harus tetap dijaga dan dipertahankan oleh pemerintah daerah guna memenuhi kebutuhan layanan sarana publik bagi masyarakat.

Sejak disahkannya Undang-undang Nomor 7 Tahun 2014 tentang Perdagangan, maka pasar tradisional telah berubah penyebutannya menjadi Pasar Rakyat dengan tetap memperhatikan kekhususan pasar rakyat terkait aspek lokasi yang bersifat tetap berupa toko/kios/los dan bentuk lainnya serta menjadi tempat 


\section{Volume 3 , Nomor 1 ,}

jual beli dengan proses tawar menawar. Memperhatikan berbagai peraturan tersebut dan kebijakan nasional dari Kabinet Kerja ditambah dengan munculnya keinginan untuk memperbaiki pengelolaan pasar rakyat menjadi lebih baik lagi. Khususnya pada saat revitalisasi / peremajaan pasar yang sudah ada maupun pada saat pembangunan pasar baru, maka beberapa pihak mengajukan inisiatif agar terbentuk Pasar rakyat, supaya tersedia sumber acuan bersama bagi semua pemangku kepentingan.

Mewujudkan tahun 2019 sebagai tahun kunjungan wisata, Pemerintah Kabupaten Situbondo termotivasi untuk mengeksplor potensi di desa Kayumas Kecamatan Arjasa dengan 4 komoditas unggulan (Jahe Merah, Pisang Kirana, Kopi dan Jeruk ). Pembangunan pasar akan didukung sebagian besar dari APBD Provinsi Jawa Timur, Alokasi Dana Desa melalui BUMDesa dan APBD Kabupaten Situbondo. Pasar rakyat ini diharapkan keberadaannya memiliki kontribusi besar terhadap pembangunan ekonomi Kabupaten Situbondo, oleh karena itu penelian akan berjalan dengan lancar.

Atas dasar kerangka pemikiran tersebut diatas, mendorong penulis untuk melakukan penelitian dengan judul ANALISIS PEKEMBANGAN PASAR PADA RENCANA PEMBANGUNAN PASAR AGROPOLITAN DESA KAYUMAS KABUPATEN SITUBONDO.

Berdasarkan uraian yang di kemukakan diatas serta atas, maka perumusan masalah dalam penelitian ini dapat diajukan sebagai berikut :

a. Bagaimana peran hubungan konsumen dapat memberikan perkembangan pasar yang ada di wilayah kayu mas?

b. Bagaimana peran hubungan pedagang bisa melakukan perkembangan pasar untuk kesejahteraan pedagang tersebut ?

c. Bagaimana kayu mas bisa dapat meningkatakan kualitas melalui perdagangan yang ada di wilayah tersebut?

\section{METODE PENELITIAN}

Kegiatan penelitian ini bertempat di desa kayumas kecamatan arjasa untuk mengeksplor potensi yang ada. Pembangunan pasar akan didukung sebagian besar dari APBD Provinsi Jawa Timur, Alokasi Dana Desa melalui 


\section{Volume 3 , Nomor 1 ,}

BUMDesa dan APBD Kabupaten Situbondo. Pasar rakyat ini diharapkan keberadaannya memiliki kontribusi besar terhadap pembangunan ekonomi Kabupaten Situbondo.

Data yang digunakan dalam kajian ini berupa data primer yang diperoleh dari hasil wawancara, serta data sekunder dari instansi terkait dan data peran dan fungsi yang terkait untuk pembangunan perkembangan pasar di Kayumas Kabupaten Situbondo.

Jenis data yang digunakan dalam penelitian ini adalah data sekunder dan data primer. Data sekunder merupakan data yang tidak diperoleh dari sumbernya langsung, melainkan sudah dikumpulkan oleh pihak lain. Metode pengumpulan data dilakukan dengan teknik dokumentasi, yaitu pengumpulan data baku yang diperoleh pada Instansi atau Organisasi yang ada, baik pemerintah maupun swasta (Muslimin, 2002:23).

Lokasi penelitian dilakukan di Kayumas Kabupaten Situbondo. Waktu penelitian dilaksanakan selama tiga bulan yang diawali pada 22 Mei 2018 sampai dengan 23 Agustus 2018.

Analisa yang digunakan adalah analisis (ANOVA). Sebuah analisis statistik yang menguji perbedaan rerata antar grup. Grup disini bisa berarti kelompok atau jenis perlakuan. Anova ditemukan dan diperkenalkan oleh seorang ahli statistik bernama Ronald Fisher.

Anova merupakan singkatan dari Analysis of Variance. Merupakan prosedur uji statistik yang mirip dengan t test. Namun kelebihan dari anova adalah dapat menguji perbedaan rerata dari dua kelompok saja.

Kegunaan anova sebagai alat analisis untuk menguji hipotesis penelitian yang mana menilai adakah perbedaan rerata antar kelompok. Hasil akhir dari analisis anova adalah nilai $\mathrm{F}$ test atau $\mathrm{F}$ hitung. 


\section{Volume 3 , Nomor 1 ,}

Juli 2019

\section{HASIL DAN PEMBAHASAN}

\section{Keadaan Umum Wilayah Kayumas Kabupaten Situbondo}

\section{Lokasi 1}

Lokasi 1 berada di Dusun Krajan Desa Kayumas, Luas lahan $=2.460$ m2, dengan ketinggian \pm 655 dpl. Disain pasar yang merupakan embrio-pasar ini sangat sederhana, hanya terdiri dari beberapa blok bangunan, yaitu :

a. Blok Los pasar untuk pedagang dan pembeli grosir

b. Blok Kios yang terdiri dari 5 unit dan toilet

c. Blok Fasilitas Umum (Mushollah)

d. Blok Kantor Pengelola dan Ruang Laktasi (ruang ibu menyusui)

e. Pos Keamanan

f. IPAL (Instalasi Pengolahan Air Limbah)

Konsep pasar yang sangat sederhana, bukan berarti tidak dilengkapi standard minimal seperti layaknya sebuah pasar.

\section{Lokasi 2}

Lokasi 2 berada di Dusun Pelleh Desa Kayumas, Luas Lahan $=26.710$ $\mathrm{m} 2$ dengan ketinggian $\pm 575 \mathrm{~m}$ dpl, Nantinya merupakan pengembangan dari Pasar di Dusun Krajan, pasar agro yang sudah ada akan dikembangkan ke arah wisata agro. Dikembangkan menjadi areal wisata agro, dengan fasilitas gardupandang dan tempat duduk di pinggir tebing yang sudah diberi TPT dan Guardrail terdiri dari :

a. Blok Los Pasar Agro (komoditas hortikultur) Grosir dan Eceran.

b. Blok Los Pasar Basah

c. Blok Los Pasar Kering

d. Blok Ruang Bersama (Pengelola, Musholah, Laktasi, Pos Ukur Ulang)

e. Blok Gardu Pandang (wisata)

f. Pos Keamanan

g. Pengelolaan Sampah dan Instalasi Pengelolaan Air Limbah 


\section{Volume 3 , Nomor 1 ,}

\section{Lokasi 3}

Lokasi 3 berada di dusun Tanah Merah Desa Kayumas, Luas Lahan = $2.500 \mathrm{~m} 2$ dengan ketinggian $\pm 419 \mathrm{~m} \mathrm{dpl}$, Merupakan pengembangan tahap berikutnya dari Lokasi-2, pasar ini diharapkan menjadi penopang kegiatan pasarpasar sebelumnya (lokasi-2/di Dusun Pelleh maupun lokasi-1/di Dusun Krajan) terdiri dari :

a. Blok Los pasar untuk pedagang dan pembeli grosir

b. Blok Kios yang terdiri dari 10 unit dan toilet

c. Blok Fasilitas Umum (Mushollah)

d. Blok Kantor Pengelola dan Ruang Laktasi

e. Pos Keamanan

f. Pengelolaan Sampah dan IPAL

g. Gardu Pandang

\section{Hasil Analisis Sosial Ekonomi}

\section{Analisis Hubungan Konsumen dengan Perkembangan Pasar}

Kriteria keputusannya adalah sebagai berikut :

- Variabel bebas (independent) dikatakan mempunyai hubungan yang signifikan terhadap variabel terikat (dependent) apabila sig $<0,05$

- Variabel bebas (independent) dikatakan tidak mempunyai hubungan yang signifikan terhadap variabel terikat (dependent) apabila sig $<0,05$

Berdasarkan hasil perhitungan diperoleh print out sebagai berikut :

Tabel 1. Perhitungan ANOVA pada Konsumen (Pelanggan) Tests of Between-Subjects Effects

Dependent Variable: Frekuensi Belanja

\begin{tabular}{|c|c|c|c|c|c|}
\hline Source & $\begin{array}{c}\text { Type III } \\
\text { of } \\
\text { Squares }\end{array}$ & df & $\begin{array}{c}\text { Mean } \\
\text { Square }\end{array}$ & F & Sig. \\
\hline Corrected & $1657.928 \mathrm{a}$ & 13 & 12 & 9.22 & .00 \\
\hline Intercept & 4220.843 & 1 & 422 & 305.3 & .00 \\
\hline $\mathrm{X} 1$ & 88.013 & 2 & 4 & 3.18 & .04 \\
\hline $\mathrm{X} 2$ & 89.572 & 2 & 4 & 3.24 & .04 \\
\hline
\end{tabular}


R Squared $=$

\begin{tabular}{|c|c|c|c|c|c|}
\hline $\mathrm{X} 3$ & 27.524 & 2 & 1 & 99 & .37 \\
\hline $\mathrm{X} 4$ & 224.414 & 3 & 7 & 5.41 & .00 \\
\hline $\mathrm{X} 5$ & 86.889 & 2 & 4 & 3.14 & .04 \\
\hline $\mathrm{X} 6$ & 92.240 & 2 & 4 & 3.33 & .04 \\
\hline Error & 1188.822 & 86 & 1 & & \\
\hline Total & 11967.000 & 100 & & & \\
\hline Corrected & $\mathbf{2 8 4 6 . 7 5 0}$ & $\mathbf{9 9}$ & & & \\
\hline
\end{tabular}

(Adjusted R Squared $=.519$ )

Sumber : data primer yang diolah, 2018

Y : Frekuensi Berbelanja di Pasar Kayumas

$\mathrm{X} 1 \quad$ : Jarak

$\mathrm{X} 2$ : Transportasi

X3 : Kebiasaan Berbelanja

X4 : Daya Tarik Pasar

X5 : Pendapatan Konsumen

X6 : Tingkat Kepedulian

Pada variabel jarak tempuh (X1) diperoleh nilai sig sebesar 0,046 yang mana nilai tersebut masih dibawah $0,05(0,046<0,05)$.

Pada variabel transportasi dengan angkutan atau kendaraan sendiri (X2) diperoleh nilai sig sebesar 0,044 yang mana nilai tersebut masih dibawah 0,05 $(0,044<0,05)$.

Pada variabel kebiasaan berbelanja (X3) diperoleh nilai sig sebesar 0,374 yang mana nilai tersebut diatas $0,05(0,374>0,05)$.

Pada variabel daya tarik pasar (X4) diperoleh nilai sig sebesar 0,002 yang mana nilai tersebut masih dibawah 0,05 $(0,002<0,05)$.

Pada variabel pendapatan masyarakat (X5) diperoleh nilai sig sebesar 0,048 yang mana nilai tersebut masih dibawah $0,05(0,048<0,05)$.

Pada variabel partisipasi atau kepedulian masyarakat (X6) diperoleh nilai sig sebesar 0,040 yang mana nilai tersebut masih dibawah 0,05 $(0,040<0,05)$. 


\section{Volume 3 , Nomor 1 ,}

Berdasarkan hasil perhitungan dengan program SPSS diperoleh nilai adjusted R Square sebesar .519 atau 0,519. Hal ini menunjukkan bahwa frekuensi pembelian dapat dijelaskan oleh variabel bebas (independent) yaitu jarak tempuh, transportasi (peranan angkutan), kebiasaan belanja, daya tarik pasar, besar pendapatan perbulan dan partisipasi masyarakat (kepedulian) adalah sebesar 51,9 $\%$ sedangkan sisanya 48,1\% dijelaskan oleh variabel yang tidak diteliti. Sehingga secara umum faktor konsumen atau masyarakat mempunyai peranan dalam pembangunan Pasar Kayumas Kabupaten Situbondo

\section{Analisis Hubungan Pedagang dengan Perkembangan Pasar}

Kriteria keputusannya adalah sebagai berikut :

- Variabel bebas (independent) dikatakan mempunyai hubungan yang signifikan terhadap variabel terikat (dependent) apabila sig $<0,05$

- Variabel bebas (independent) dikatakan tidak mempunyai hubungan yang signifikan terhadap variabel terikat (dependent) apabila sig $>0,05$

Berdasarkan hasil perhitungan diperoleh print out sebagai berikut :

Tabel 2. Perhitungan ANOVA pada Pedagang Test of Between - Subjects Effects

\begin{tabular}{|c|c|c|c|c|c|}
\hline Source & $\begin{array}{c}\text { Type III of } \\
\text { Squares }\end{array}$ & df & $\begin{array}{c}\text { Mean } \\
\text { Square }\end{array}$ & F & Sig. \\
\hline Corrected & $28651.864 \mathrm{a}$ & 14 & 2046. & 4.07 & .000 \\
\hline Intercept & 38686.271 & 1 & 38686. & 77.03 & .000 \\
\hline $\mathrm{X} 1$ & 5491.729 & 4 & 1372. & 2.73 & .044 \\
\hline $\mathrm{X} 2$ & 4541.244 & 2 & 2270. & 4.52 & .018 \\
\hline $\mathrm{X} 3$ & 5100.792 & 2 & 2550. & 5.07 & .012 \\
\hline $\mathrm{X} 4$ & 1115.049 & 2 & 557. & 1.11 & .0341 \\
\hline $\mathrm{X} 5$ & 4160.278 & 2 & 2080. & 4.14 & .024 \\
\hline $\mathrm{X} 6$ & 7410.533 & 2 & 3705. & 7.37 & .002 \\
\hline Error & 17576.156 & 35 & 502. & & \\
\hline Total & 209477.000 & 50 & & & \\
\hline Corrected & $\mathbf{4 6 2 2 8 . 0 2 0}$ & $\mathbf{4 9}$ & & & \\
\hline
\end{tabular}

Dependent Variable; Frekuensi Transaksi

R Squared $=.410($ Adjusted R Squared $=.468)$ 


\section{Volume 3 , Nomor 1 ,}

Sumber : data primer yang diolah, 2018

Dimana :

Y : Jumlah Transaksi

X1 : Barang Dagangan

X2 : Lama Berjualan

X3 : Perolehan Barang Dagangan

X4 : Metode Penyerahan Barang

X5 : Modal Berdagang

X6 : Nilai Transaksi

Pada variabel jenis barang dagangan (X1) diperoleh nilai sig sebesar 0,044 yang mana nilai tersebut masih dibawah $0,05(0,044<0,05)$.

Pada variabel lama berdagang (X2) diperoleh nilai sig sebesar 0,018 yang mana nilai tersebut masih dibawah $0,05(0,018<0,05)$.

Pada variabel tempat memperoleh barang atau darimana barang dagangan (X3) tersebut didapatkan diperoleh nilai sig sebesar 0,012 yang mana nilai tersebut masih di bawah $0,05(0,018<0,05)$.

Pada variabel cara penyampaian barang kepada konsumen (X4) diperoleh nilai sig sebesar 0,341 yang mana nilai tersebut masih diatas $0,05(0,341>0,05)$.

Pada variabel modal yang digunakan untuk berdagang (X5) diperoleh nilai sig sebesar 0,024 yang mana nilai tersebut masih dibawah $0,05(0,024<0,05)$.

Pada variabel nilai transaksi (X6) diperoleh nilai sig sebesar 0,002 yang mana nilai tersebut masih dibawah $0,05(0,002<0,05)$. 


\section{Volume 3 , Nomor 1 ,}

Berdasarkan hasil perhitungan dengan program SPSS diperoleh nilai adjusted R Square sebesar .468 atau 0,468. Hal ini menunjukkan bahwa frekuensi transaksi para pedagang di Pasar Kayumas dapat dijelaskan oleh variabel bebas (independent) yaitu jenis dagangan, lama berdagang, sumber memperoleh barang dagangan, cara penyampaian barang, modal dagangan dan nilai transaksi adalah sebesar $46,8 \%$ sedangkan sisanya 53,2\% dijelaskan oleh variabel yang tidak diteliti. Sehingga secara umum faktor pedagang mempunyai peranan dalam pembangunan Pasar Kayumas Kabupaten Situbondo.

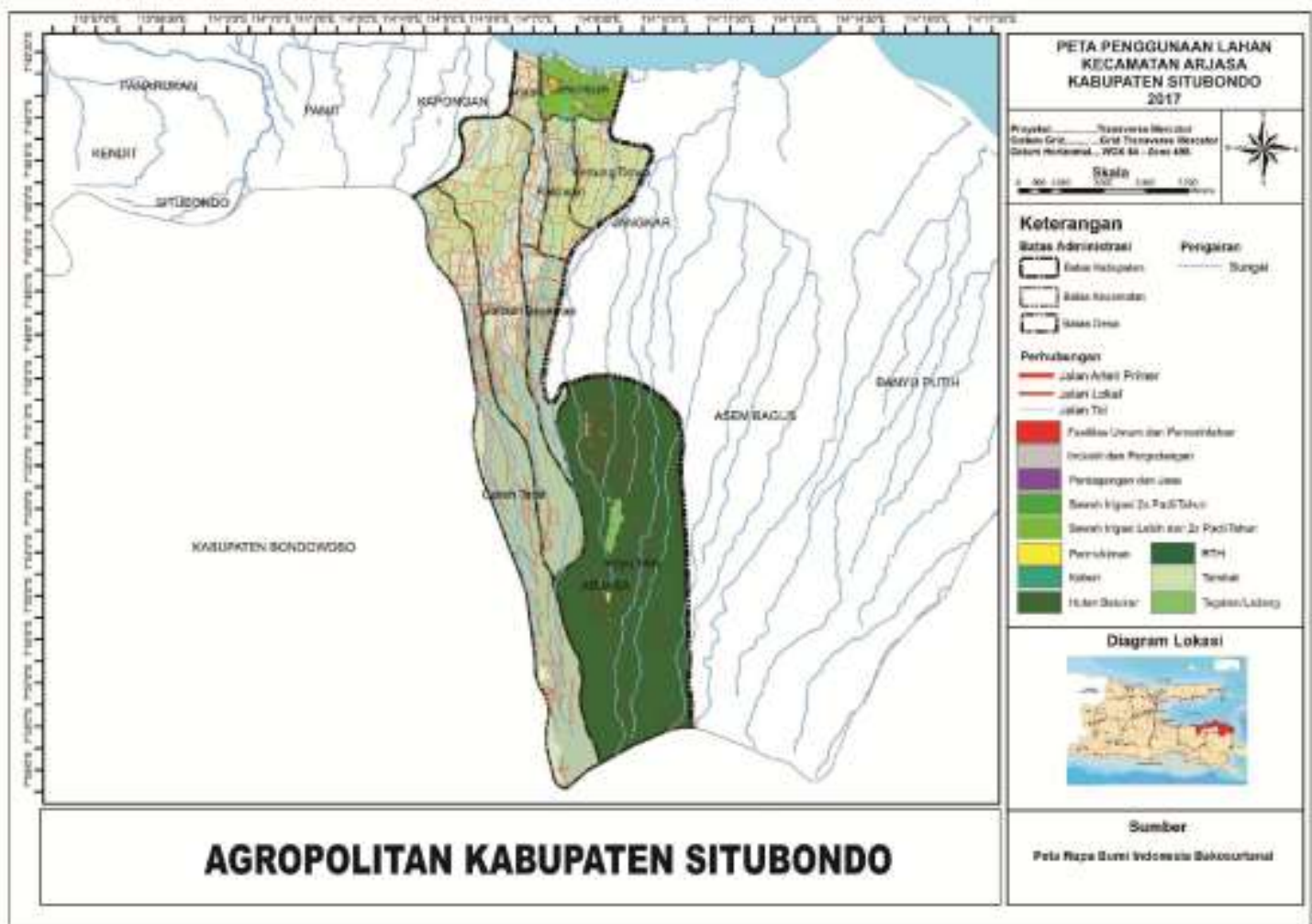

Gambar 1. Pasar Agropolitan Kayumas Kecamatan Arjasa Kab. Situbondo

Berdasarkan uraian diatas menunjukkan bahwa pembangunan Pasar di Desa Kayumas Kabupaten Situbondo dari aspek ekonomi dan sosial adalah dapat diterima. Hal didasarkan pada adanya peningkatan - peningkatan yang signifikan terhadap perbaikan dan peningkatan taraf hidup serta perbaikan pada aspek sosial dan budaya. Sehingga pembangunan pasar di Desa Kayumas Kabupaten 


\section{Volume 3 , Nomor 1 ,}

Situbondo sangat berdampak signifikan pada perbaikan ekonomi dan sosial di daerah sekitar pada khususnya.

\section{Pembahasan}

Kawasan pasar berbasis agrowisata yang akan dikembangkan terletak di Desa Kayumas Kecamatan Arjasa Kabupaten Situbondo dengan gambaran peta sebagai berikut:

Dari peta tersebut di atas secara topografis, ketinggian desa dari permukaan laut, jarak dari pusat pemerintahan dan luas desa adalah sebagai berikut:

Tabel 3. Kondisi Geografis Desa Kayumas

\begin{tabular}{|c|l|l|}
\hline No. & \multicolumn{1}{|c|}{ Keterangan } & \multicolumn{1}{c|}{ Posisi dan Ukuran } \\
\hline 1 & $\begin{array}{l}\text { Ketinggian desa dari } \\
\text { permukaan laut }\end{array}$ & $>750-1550 \mathrm{dpl}$ \\
\hline 2 & Letak & Bukian pantai \\
\hline 3 & Topografi & Berbukit \\
\hline 4 & $\begin{array}{l}\text { Jarak terdekat dengan } \\
\text { kecamatan }\end{array}$ & 26.0 \\
\hline 5 & $\begin{array}{l}\text { Jarak terdekat dengan } \\
\text { kabupaten }\end{array}$ & 41.0 \\
\hline 6 & $\begin{array}{l}\text { Jarak terdekat dengan } \\
\text { provinsi }\end{array}$ & 248.0 \\
\hline 7 & Luas desa & 76.29 \\
\hline 8 & Batas sebelah Timur & Kecamatan Asembagus \\
\hline 9 & Batas sebelah Utara & Kecamatan Jangkar \\
\hline 10 & Batas sebelah Barat & $\begin{array}{l}\text { Ds. Curahtatal, Ds. } \\
\text { Jatisari dan Ds. } \\
\text { Bayeman Kec. Arjasa }\end{array}$ \\
\hline 11 & Batas sebelah Selatan & $\begin{array}{l}\text { Kec. Sempol Kab. } \\
\text { Bondowoso }\end{array}$ \\
\hline
\end{tabular}

Sumber: Situbondo dalam Angka 2017

Adapun dusun di Desa Kayumas terdiri dari Dusun Tanah Merah, Tunggul Gunung, Pelleh, Krajan, Kayumas, ALun - alun, Cottok, dan Dusun Sokmailang. Dari delapan dusun di Desa Kayumas selebihnya akan dilakukan pengamatan dan analisis berdasarkan kriteria penilaian yaitu aspek aksesibilitas, sarana dan prasarana, produktivitas pertanian dan potensi lain yang ada. Konsep pasar memang sangat sederhana, tapi bukan berarti tidak dilengkapi standard 


\section{Volume 3 , Nomor 1 ,}

minimal seperti layaknya sebuah pasar. Desain pasar sudah terdiri dari beberapa blok bangunan blok los pasar untuk pedagang dan pembeli grosir, blok kios yang terdiri dari 5 unit dan toilet, blok fasilitas umum (mushollah), blok kantor pengelola dan ruang laktasi dan pos keamanan dan IPAL (Instalansi Pembuangan Air Limbah).

Selanjutnya adalah upaya peningkatan dan pemerataan fasilitas yang mendesak untuk dilakukan. Akses menuju pasar rakyat relatif cukup mudah dan dekat dengan masyarakat hanya yang menjadi kendala adalah lebar jalan yang sempit. Sehingga akan menyulitkan jika ada kendaraan beroda 4 yang berlawanan arah saling melewati lokasi tersebut. Aksesibilitas akan menjadi prioritas utama Pemerintah Kabupaten Situbondo melalui dinas terkait dalam rangka pendirian pasar rakyat di Desa Kayumas.

\section{PENUTUP}

Berdasarkan hasil Analisis Pekembangan Pasar Pada Rencana Pembangunan Pasar Agropolitan Desa Kayumas Kabupaten Situbondo dapat disimpulkan diantaranya, yaitu :

1. Analisis hubungan konsumen dengan perkembangan pasar, Berdasarkan hasil perhitungan dengan program SPSS diperoleh nilai adjusted R Square sebesar .519 atau 0,519. Hal ini menunjukkan bahwa frekuensi pembelian dapat dijelaskan oleh variabel bebas (independent) yaitu jarak tempuh, transportasi (peranan angkutan), kebiasaan belanja, daya tarik pasar, besar pendapatan perbulan dan partisipasi masyarakat (kepedulian) adalah sebesar 51,9\% sedangkan sisanya 48,1 \% dijelaskan oleh variabel yang tidak diteliti. Sehingga secara umum faktor konsumen atau masyarakat mempunyai peranan dalam pembangunan Pasar Kayumas Kabupaten Situbondo

2. Analisis hubungan pedagang dengan perkembangan pasar, Berdasarkan hasil perhitungan dengan program SPSS diperoleh nilai adjusted R Square sebesar .468 atau 0,468. Hal ini menunjukkan bahwa frekuensi transaksi para pedagang di Pasar Kayumas dapat dijelaskan oleh variabel bebas (independent) yaitu jenis dagangan, lama berdagang, sumber memperoleh 


\section{Volume 3 , Nomor 1 ,}

barang dagangan, cara penyampaian barang, modal dagangan dan nilai transaksi adalah sebesar 46,8 \% sedangkan sisanya 53,2 \% dijelaskan oleh variabel yang tidak diteliti. Sehingga secara umum faktor pedagang mempunyai peranan dalam pembangunan Pasar Kayumas Kabupaten Situbondo.

3. Pembangunan Pasar Kayumas akan terjadi pergeseran dan peningkatan pada bidang sosial dan budaya. Dampaknya adalah terjadi perbaikan dan peningkatan - peningkatan sarana dan prasarana sehingga hal ini akan berdampak terhadap perbaikan kehidupan sosial bagi masyarakat di sekitar pasar. Berdasarkan uraian diatas menunjukkan bahwa pembangunan Pasar Kayumas Kabupaten Situbondo dari aspek ekonomi dan social adalah dapat diterima. Hal berdasarkan pada adanya peningkatan - peningkatan yang signifikan terhadap perbaikan dan peningkatan taraf hidup serta perbaikan pada aspek sosial dan budaya. Sehingga pembangunan Pasar Kayumas Kabupaten Situbondo sangat berdampak signifikan pada perbaikan ekonomi di daerah sekitar pasar.

\section{Saran}

Berdasarkan dari kesimpulan diatas, maka ada beberapa saran yang harus dilakukan untuk penelitian Analisis Pekembangan Pasar Pada Rencana Pembangunan Pasar Agropolitan Desa Kayumas Kabupaten Situbondo, diantaranya sebagai berikut :

1. Pemerintah harus segera melakukan program untuk dapat merehab pasar yang layak untuk menjadi pasar agropolitan menjadi lebih baik lagi.

2. Banyak sekali masyarakat yang antusias untuk melanjutkan dan memperbaiki pasar rakyat menjadi lebih baik lagi.

3. Dengan terlaksananya program tersebut, akan dapat memperbaiki perekonomian di daerah sekitar pasar kayumas Kabupaten Situbondo. 


\section{DAFTAR PUSTAKA}

Andreas Yuniman Tjandra dan Marinus Wahjudi. 2006. Analisa Perkembangan Pasar Tradisional Studi Komparatif Terhadap Pengguna Ruang Komersial di Pasar Atum, Pasar Turi, dan Pasar Wonokromo. URL: www.bibsonomy.org.

Blair, John P. 1995. Local Economic Development: Analysis and Practice, California, USA: Sage Publications Inc.

Campbell, R. McConnell and Stanley L. Brue. 1990. Economics: Principles, Problems and Policies. McGraw-Hill Publishing Company.

Daldjoeni, N. 1987. Geografi Kota dan Desa. Bandung: Penerbit Alumni. Damsar. 1997. Sosiologi Ekonomi. Jakarta: Penerbit PT Raja Grafindo Persada. David Dewar and Vanessa Watson, 1990, Urban Market Developing Informal Retailing, London, Rontledge

Danisworo, Muhammad / Widjaja Martokusumo, 2000. Revitalisasi Kawasan Kota Sebuah Catatan dalam Pengembangan dan Pemanfaatan Kawasan Kota, www.urdi.org (urban and reginal development institute, 2000).

De Chiara, Joseph dan E. Lee Coppelman. 1999. Standar Perencanaan Tapak. Jakarta: Penerbit PT Erlangga.

Dinas Pekerjaan Umum Cipta Karya Kabupaten Musi Banyuasin. Penyusunan Studi LARAP Pembangunan Pasar Tradisional Randik - Sekayu. http://www.pu.go.id/publik/usdrp/Musi\%2520Banyuasin/Larap/Bab1.

Eisner, Simon. 1993. The Urban Pattern, 6th Edition. New York: WileyPublishing.

Ginanjar, Nugraha Jiwapraja. 1980. Masalah Ekonomi Mikro. Jakarta: Acro.

Ghozali, Imam, 2001, Aplikasi Analisa Multivariate Dengan Program SPSS, Badan Penerbit Universitas Diponegoro

Indriantoro, Nur dan Supomo, Bambang, 2002, Metodologi Penelitian Bisnis untuk Akuntansi dan Manajemen, BPFE, Yogyakarta.

Jayadinata, Johara T. 1985. Pembangunan Desa dalam Perencanaan. Bandung: ITB , 1999. Tata Guna Tanah dalam Perencanaan Pedesaan, Perkotaan dan Wilayah. Bandung: Penerbit ITB.

Keputusan Menteri Pekerjaan Umum Nomor 378/KPTS/1987, Tanggal 3 


\section{Volume 3 , Nomor 1 ,}

Agustus 1987 tentang Pengesahan 33 Standar Konstruksi Bangunan di Indonesia, Lampiran Nomor 22.

Kodoatie, Robert J. 2003. Manajemen dan Rekayasa Infrastruktur. Yogyakarta : Pustaka Pelajar.

Kottler, Philip et al. 1998. Marketing Places: Attracting Investment, Industry and Tourism to Cities, State and Nations. New York: The Free Press Division of Macmillan Inc.

Kottler, Philip and Gary Amstrong. 2001. Prinsip-prinsip Pemasaran. Jakarta: Penerbit PT Erlangga.

L.V.Ratna Devi S, Revitalisasi Pasar Tradisional Pada Masyarakat Modern, Diskusi Bulanan Jurusan Sosiologi - Fisip Universitas Sebelas Maret

Miles, Mike E.. 1999. Real Estate Development, Principles and Process. Washington DC: Urban Land Institute.

Mudradjad Kuncoro. 2008. Strategi Pengembangan Pasar Modern dan Tradisional, Gramedia Pustaka Utama

Mursid, M. 1997. Manajemen Pemasaran. Jakarta: Penerbit Bumi Aksara. Moersid, Adhi, 1995, Pasar Tradisional di Persimpangan Jalan (makalah), Palembang, Forum Musda IAI cabang Sumatra Selatan

Nazir, Moh. 2003. Metode Penelitian. Jakarta: Penerbit Ghalia Indonesia. Ristantyo, Yanuar. 2004. "Evaluasi Alternatif Lokasi Pasar Umum Sayur di Kota Surabaya." Tugas Akhir tidak diterbitkan, Program Studi Teknik Perencanaan Wilayah dan Kota, Fakultas Teknik Universitas Diponegoro, Semarang

Riyanto, Bambang, 2005, Dasar - Dasar Pembelanjaan Perusahaan, Liberty, Yogyakarta.

Sugiyono, 2002, Statistika untuk Penelitian, CV. Alfabeta, Bandung.

Stanton, William J, 2006, Prinsip Pemasaran, Jilid I (Edisi Ketujuh), Erlangga, Jakarta.

Swastha DH, Basu dan Handoko, T Hani, 1997, Manajemen Pemasaran Analisa Perilaku Konsumen, Edisi 2 Yogyakarta. 